\title{
Siberian Fan Reliefs
}

\author{
Olga G. Gladysheva ${ }^{1}$, Alexander Yastrebov ${ }^{2}$ \\ ${ }^{1}$ Department of Astrophysics, Ioffe Institute, St. Petersburg, Russia; ${ }^{2}$ Krypton Ltd., Bryansk, Russia \\ Correspondence to: Olga G. Gladysheva, Olga.gladysheva@mail.ioffe.ru \\ Keywords: Siberian Fan Reliefs, Tunguska Catastrophe
}

Received: July 26, $2021 \quad$ Accepted: August 23, $2021 \quad$ Published: August 26, 2021

Copyright $\odot 2021$ by author(s) and Scientific Research Publishing Inc.

This work is licensed under the Creative Commons Attribution International License (CC BY 4.0).

http://creativecommons.org/licenses/by/4.0/

\section{(c) (i) Open Access}

\section{ABSTRACT}

Unusual reliefs on the Earth's surface were found in aerial photographs of Eastern Siberia in the late $20^{\text {th }}$ century. These reliefs consist of several tens (up to hundreds) of stripes that have arisen as a result of the destruction of vegetation and the surface layer of the ground. Structures of stripes are extended, ranging in size from $6 \mathrm{~km}$ to $\geq 20 \mathrm{~km}$, with a width of several kilometers. Every strip (scratch on the ground) is roughly estimated to be up to $50 \mathrm{~m}$ wide and $\geq 500 \mathrm{~m}$ long. The stripes start from one edge of the relief and stretch at intervals to the other, slightly diverging symmetrically from the central axis. It was determined that these reliefs are not associated with the movement of soil (avalanches, mudflows) or with the impact of air currents (hurricanes, storm, tornado). Geographically, these structures of stripes are located within a circle with a radius of $770 \mathrm{~km}$, described around the epicenter of the Tunguska catastrophe.

\section{INTRODUCTION}

Reliefs on the Earth's surface, the configuration of which is difficult to explain by the influence of known natural forces were discovered by A. P. Lopatin and L. M. Uskova [1], when they studied aerial photo images in the 1990s. These reliefs, which are a system of stripes, are located in the interfluvial area of the Yenisei, Angara, Lena and Podkamennaya Tunguska rivers.

The given reliefs show a specific destruction of the surface layer of the ground and woody vegetation in territories tens of kilometers long and several kilometers wide. On the archival images of the Google Earth Service, one can see a fan-shaped pattern consisting of stripes that resemble scratches in appearance against the general green background of the taiga. The stripes differ from the surrounding area covered with coniferous forests in the color of the image. The stripes range in color from white to reddish, most likely due to soil and topsoil removal; the color is determined by the color of the underlying rock. The stripes are not parallel; they tend to deviate symmetrically from the central axis of the structure.

These reliefs on the earth's surface were clearly visible in the photographs of the late twentieth century. Clearings (glades) predominated on them at that time and young small-leaf and shrub growth were developed [1]. On modern maps, these formations are practically indistinguishable or read with difficulty 
against the background of coniferous taiga forests. It was suggested that these reliefs may be related to the fall of the Tunguska cosmic body, that is, they were formed in 1908 [1].

At present, according to V. V. Burmakin, it is proposed that more than 30 reliefs be attributed to these so-called Siberian fans. Only 15 of the most characteristic reliefs will be considered in this work to determine the features of their shape and location.

\section{FAN RELIEFS}

\subsection{Kasskoye}

The Kasskoye formation has a maximum length of about $23 \mathrm{~km}$ with a maximum width of about 4 $\mathrm{km}$. As you can see in Figure 1, the range of heights at which this system of stripes is located ranges from 150 to $190 \mathrm{~m}$ above sea level. Surprisingly, the large elevation differences along the entire formation (bottom panels in Figure 1) practically do not affect the pattern of the structure; the stripes are interrupted only when crossing streams.

\subsection{Kazhma}

The Kazhma formation is traced over $17 \mathrm{~km}$ in length (Figure 2). It was investigated in 1996-1997 by expeditions led by Yu. D. Lavbin. The forest fell down in the area of this system of stripes, and the tops of the lying trees were directed to the northeast [1]. Analyzing the images, it can be noted that the slopes of the western exposure were subjected to stronger damage.

\subsection{Lendakha-Big Pit}

This formation located between the Lendakha River and the Big Pit River (Figure 3). The coordinates of the image are $59^{\circ} 05^{\prime} 42.94 " \mathrm{~N} ; 93^{\circ} 10^{\prime} 52.91^{\prime \prime} \mathrm{E}$. The length of the strip system is up to $6 \mathrm{~km}$, the width is $\sim 2$ $\mathrm{km}$.

\subsection{Sedelochny}

The formation located near the Sedelochny stream is shown in Figure 4. The coordinates of the image are $55^{\circ} 00^{\prime} 03.56^{\prime \prime} \mathrm{N} ; 96^{\circ} 19^{\prime} 03.08^{\prime \prime} \mathrm{E}$.

All the structures of stripes considered above have an elongated shape, to one degree or another, close to an ellipse. The maximum size of these formations can be defined as the central axis. Rays (stripes or scratches) fan out along this entire axis, starting at one end, which can be defined as the initial zone. In some structures, diverging stripes are traced from the initial zone along the entire length of the formation; in others, stripes diverge from different parts of the central axis. According to rough estimates, the width of the stripes can reach $50 \mathrm{~m}$ with a length of $\geq 500 \mathrm{~m}$. It should be noted that according to the height profiles in Figures 1-4, the terrain both decreases and increases as we move away from the initial zone along the central axis.

\section{SUMMARY MAP}

An azimuth was determined for each structure of stripes. It is the angle between the geographic meridian (northward direction) and the central axis (away from the initial zone). Coordinates of the formations and its azimuths are given in Table 1. The location of the Siberian fan reliefs on the terrain map is shown in Figure 5.

As you can see in Figure 5, all the considered structures of stripes are located in the territory bounded from the south by $54^{\circ} 50^{\prime}$ north latitude, from the north $-60^{\circ} 10^{\prime} \mathrm{N}$, from the west $-89^{\circ} 50^{\prime}$ east longitude, and from the east $-108^{\circ} 10^{\prime} \mathrm{E}$. Since the connection of the Siberian fan reliefs with the Tunguska event is assumed, it can be noted that all structures are located south of the epicenter of the Tunguska catastrophe and are at a distance of $\leq 770 \mathrm{~km}$ from it. 

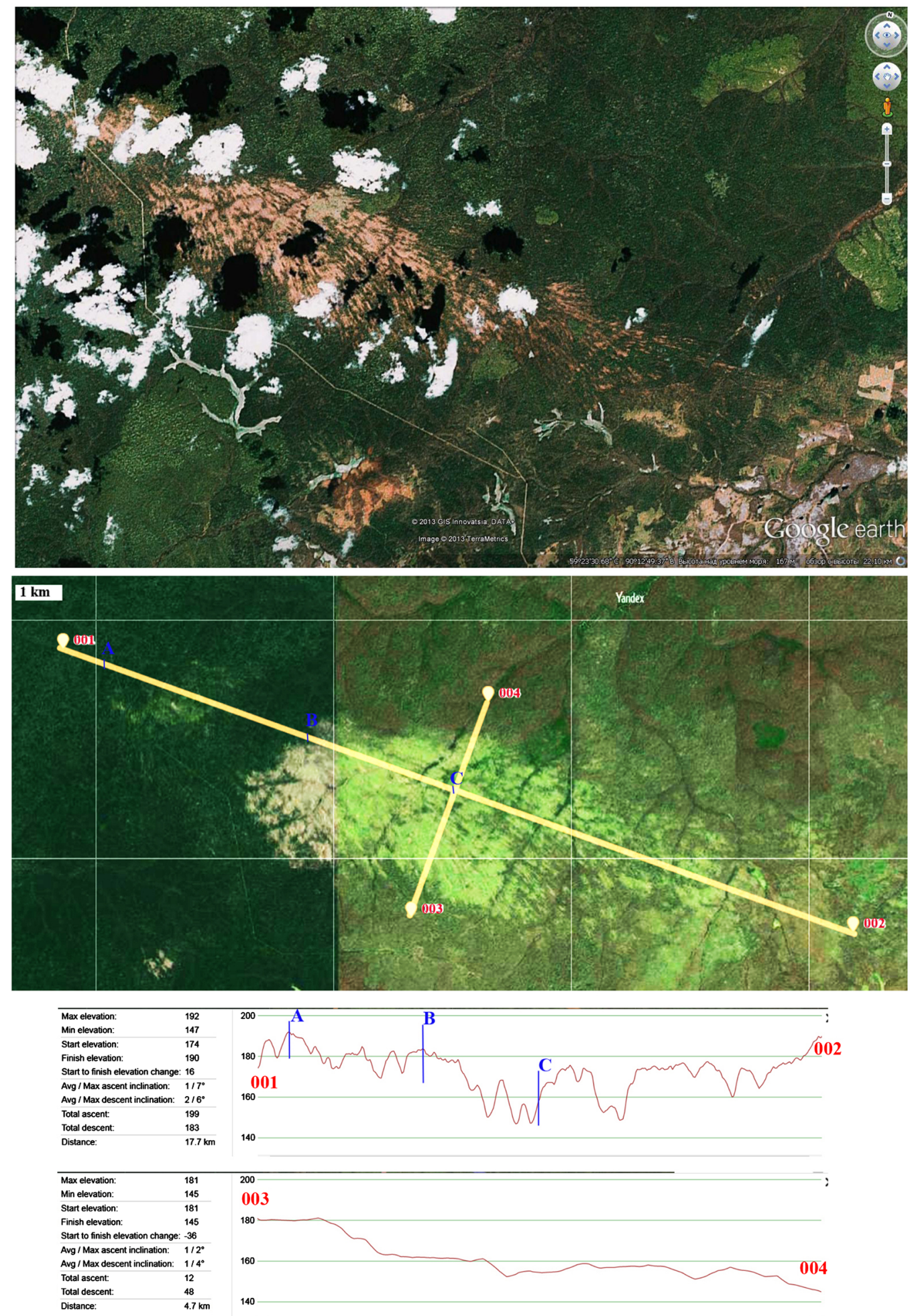

Figure 1. The Kasskoye formation. Top panel-archival image from Google Earth Service courtesy of V. V. Burmakin. The photo was taken from a height of $22.10 \mathrm{~km}$. The coordinates of the image are $59^{\circ} 23^{\prime} 30.68^{\prime \prime N}$; $90^{\circ} 12^{\prime} 49.37^{\prime E}$. Middle panel-modern view of the Earth's surface (from Yandex Satellite Maps). Elevation profiles (bottom panels) are plotted along the lines shown in the middle panel using the Nakarte.me application. 

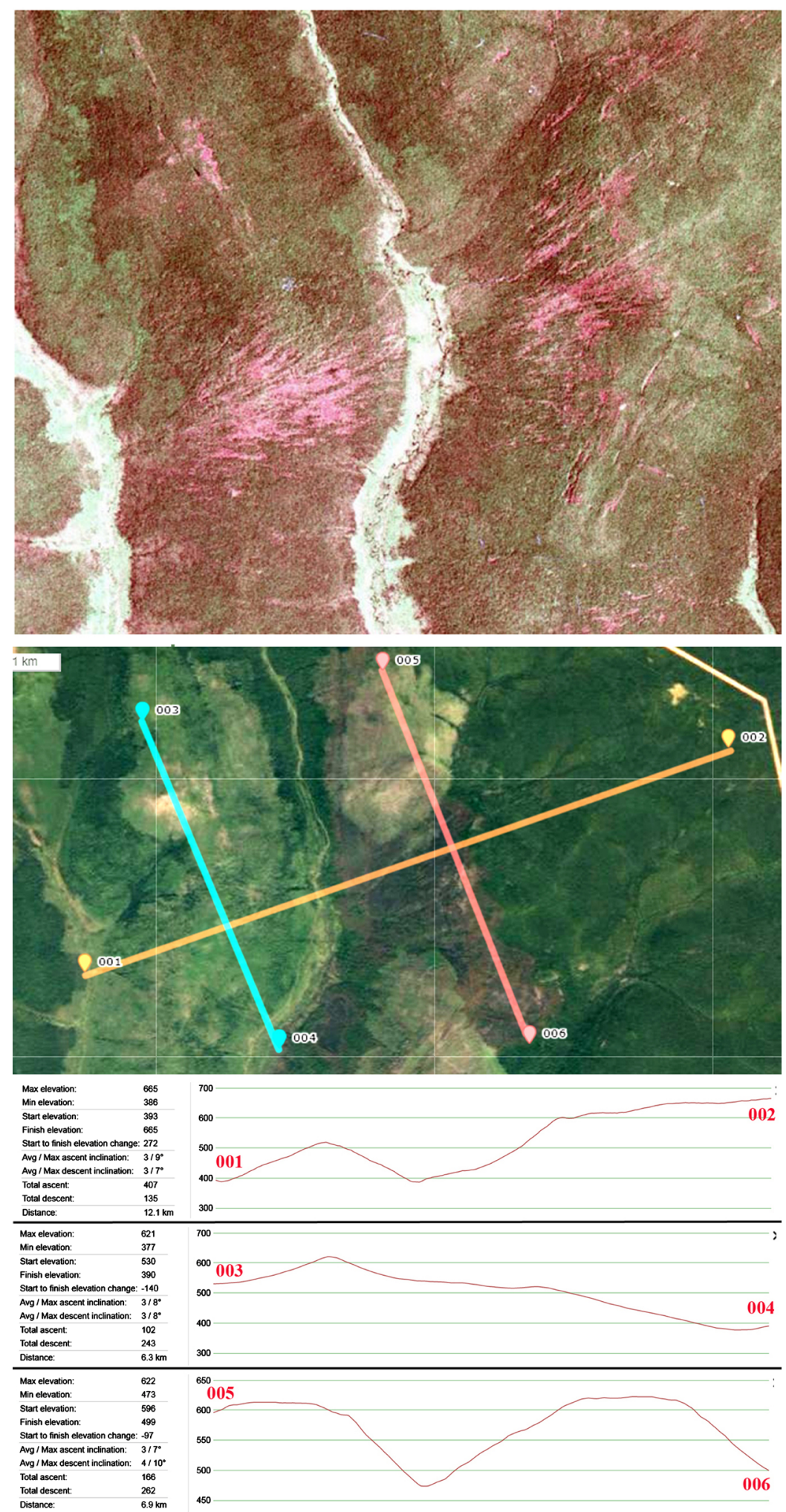

Figure 2. The Kazhma formation. Top panel-archival image of $70 \mathrm{~s}-80 \mathrm{~s}$ courtesy of V. V. Burmakin. The coordinates of the image are $59^{\circ} 36^{\prime} 48.96^{\prime \prime} \mathrm{N} ; 96^{\circ} 05^{\prime} 30.90^{\prime \prime E}$. Middle panel-modern view according to Google Satellite. Elevation profiles (bottom panels) are plotted along the lines shown in the middle panel using the Nakarte.me application. 


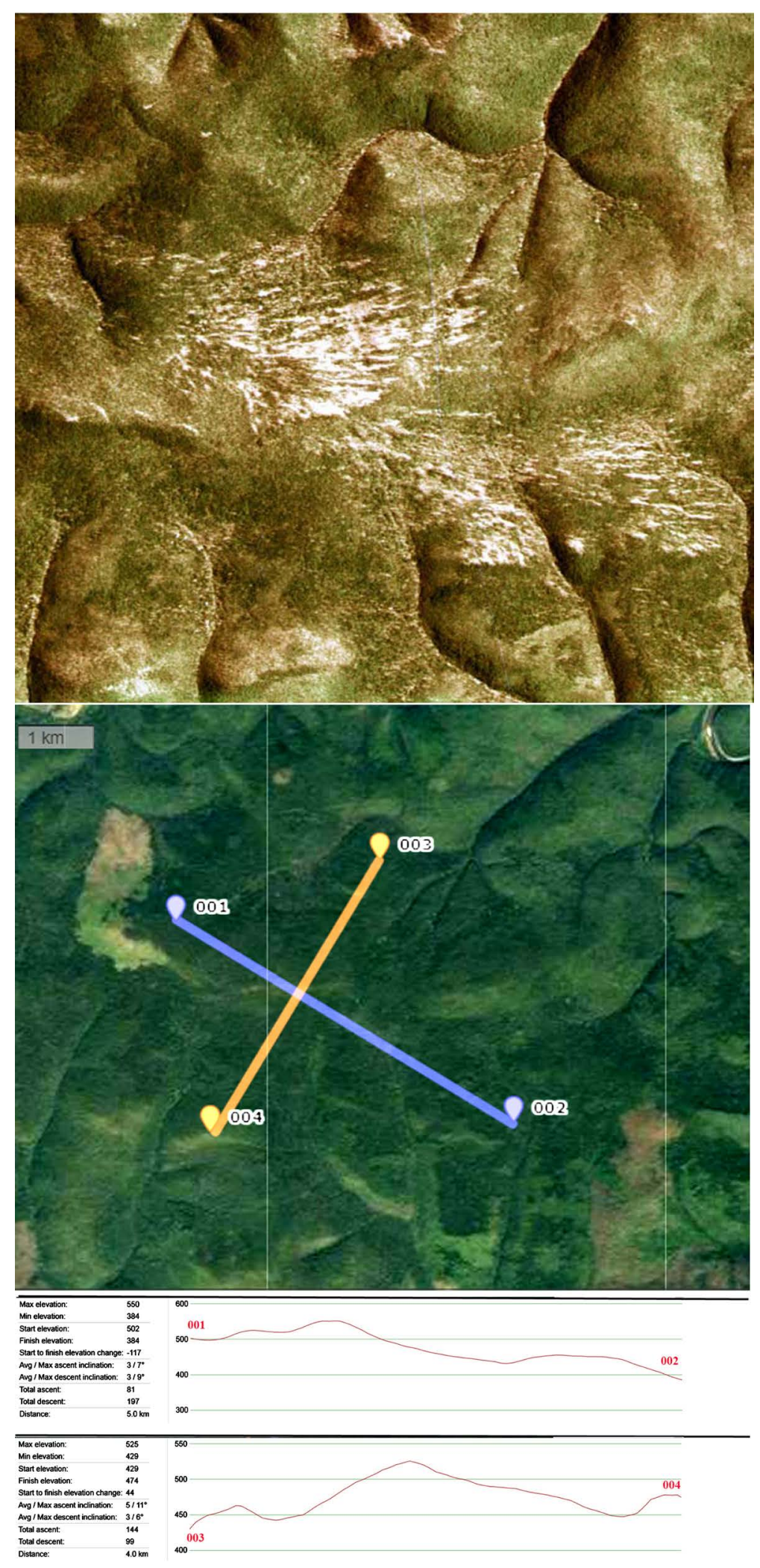

Figure 3. Formation Lendakha-Big Pit. Top panel-archival image (Lopatin, Uskova, 2004) courtesy of V. V. Burmakin. Middle panel-modern view from Google Satellite. Elevation profiles (bottom panels) are plotted along the lines shown in the middle panel using the Nakarte.me application. 

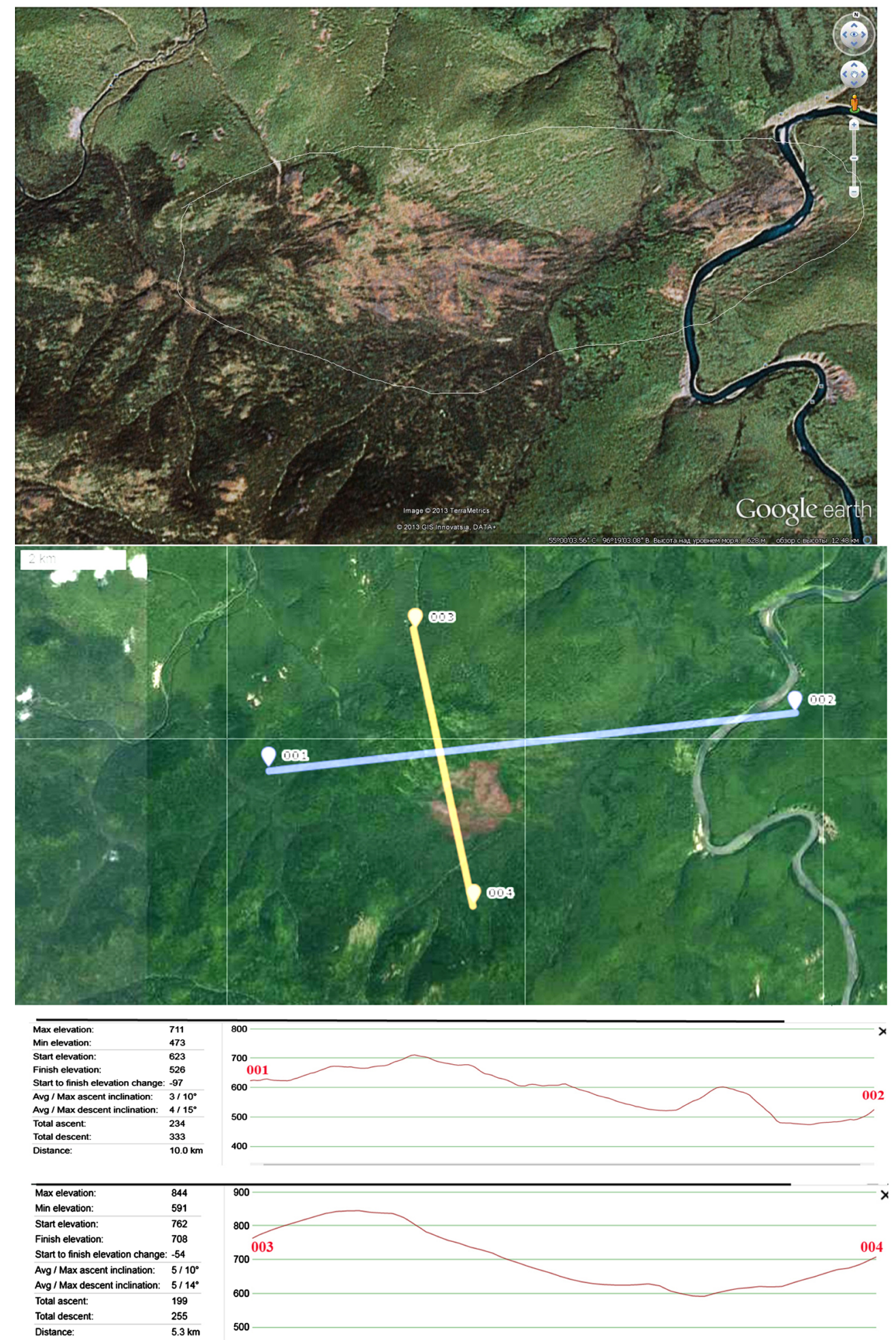

Figure 4. Formation on the Sedelochny stream. Top panel-archival image from Google Earth Service taken from a height of $12.48 \mathrm{~km}$ courtesy of $\mathrm{V}$. V. Burmakin. The coordinates of the image are $55^{\circ} 00^{\prime} 03.56^{\prime \prime N} ; 96^{\circ} 19^{\prime} 03.08^{\prime \prime E}$. Middle panel-modern view from Yandex Satellite Maps. Elevation profiles (bottom panels) are plotted along the lines shown in the middle panel using the Nakarte.me application. 
Table 1. Siberian fan reliefs.

\begin{tabular}{|c|c|c|c|}
\hline No. & Formation & Coordinates & Azimuth $^{\star}$ \\
\hline 001 & Kazhma & $59^{\circ} 36^{\prime} 48.96^{\prime \prime N} ; 96^{\circ} 05^{\prime} 30.90^{\prime \prime} \mathrm{E}$ & $69^{\circ} \pm 5^{\circ}$ \\
\hline 002 & Lendakha-Big Pit & $59^{\circ} 05^{\prime} 42.94^{\prime \prime N} ; 93^{\circ} 10^{\prime} 52.91^{\prime \prime} \mathrm{E}$ & $113^{\circ} \pm 7^{\circ}$ \\
\hline 003 & Kasskoye & $59^{\circ} 23^{\prime} 30.68^{\prime \prime N} ; 90^{\circ} 12^{\prime} 49.37^{\prime \prime E}$ & $116^{\circ} \pm 5^{\circ}$ \\
\hline 004 & Sym2 & $60^{\circ} 07^{\prime} 29.92^{\prime \prime N} ; 89^{\circ} 53^{\prime} 08.12^{\prime \prime} \mathrm{E}$ & $92^{\circ} \pm 8^{\circ}$ \\
\hline 005 & Sym3 & $60^{\circ} 09^{\prime} 40.18^{\prime \prime N} ; 90^{\circ} 12^{\prime} 41.82^{\prime \prime} \mathrm{E}$ & $86^{\circ} \pm 4^{\circ}$ \\
\hline 006 & Sym & $60^{\circ} 09^{\prime} 19.29^{\prime \prime N} ; 90^{\circ} 03^{\prime} 32.77^{\prime \prime} \mathrm{E}$ & $80^{\circ} \pm 7^{\circ}$ \\
\hline 007 & Sedelochny & $55^{\circ} 00^{\prime} 03.56^{\prime \prime N} ; 96^{\circ} 19^{\prime} 03.08^{\prime \prime} \mathrm{E}$ & $85^{\circ} \pm 5^{\circ}$ \\
\hline 008 & Agul-Chukhlaikha & $54^{\circ} 54^{\prime} 16.52^{\prime \prime N} ; 96^{\circ} 40^{\prime} 50.78^{\prime \prime} \mathrm{E}$ & $50^{\circ} \pm 20^{\circ}$ \\
\hline 009 & Tumanshet & $54^{\circ} 57^{\prime} 31.20^{\prime \prime N} ; 96^{\circ} 51^{\prime} 53.52^{\prime \prime} \mathrm{E}$ & $103^{\circ} \pm 7^{\circ}$ \\
\hline 010 & Right bank of the Lena river & $58^{\circ} 46^{\prime} 09.96^{\prime \prime N} ; 111^{\circ} 20^{\prime} 00.67^{\prime \prime} \mathrm{E}$ & $37^{\circ} \pm 5^{\circ}$ \\
\hline 011 & Lena river 1 & $58^{\circ} 39^{\prime} 00.54^{\prime \prime N} ; 110^{\circ} 47^{\prime} 45.66^{\prime \prime} \mathrm{E}$ & $15^{\circ} \pm 20^{\circ}$ \\
\hline 012 & Lena river2 & $56^{\circ} 27^{\prime} 02.25^{\prime \prime} \mathrm{N} ; 106^{\circ} 42^{\prime} 40.99^{\prime \prime} \mathrm{E}$ & $4^{\circ} \pm 10^{\circ}$ \\
\hline 013 & B. Vereya-Ilim & $55^{\circ} 59^{\prime} 00.11^{\prime \prime N} ; 104^{\circ} 44^{\prime} 41.86^{\prime \prime} \mathrm{E}$ & $12^{\circ} \pm 5^{\circ}$ \\
\hline 014 & Gorely-Kelora-Lena & $54^{\circ} 51^{\prime} 04.75^{\prime \prime N} ; 106^{\circ} 19^{\prime} 40.78^{\prime \prime} \mathrm{E}$ & $100^{\circ} \pm 7^{\circ}$ \\
\hline 015 & Kulebyachikha-Lena River & $57^{\circ} 41^{\prime} 26.48^{\prime \prime N} ; 108^{\circ} 01^{\prime} 24.31^{\prime \prime E}$ & $55^{\circ} \pm 10^{\circ}$ \\
\hline
\end{tabular}

*The last column is the angle between the direction of the central axis of the structure and the direction to the north.

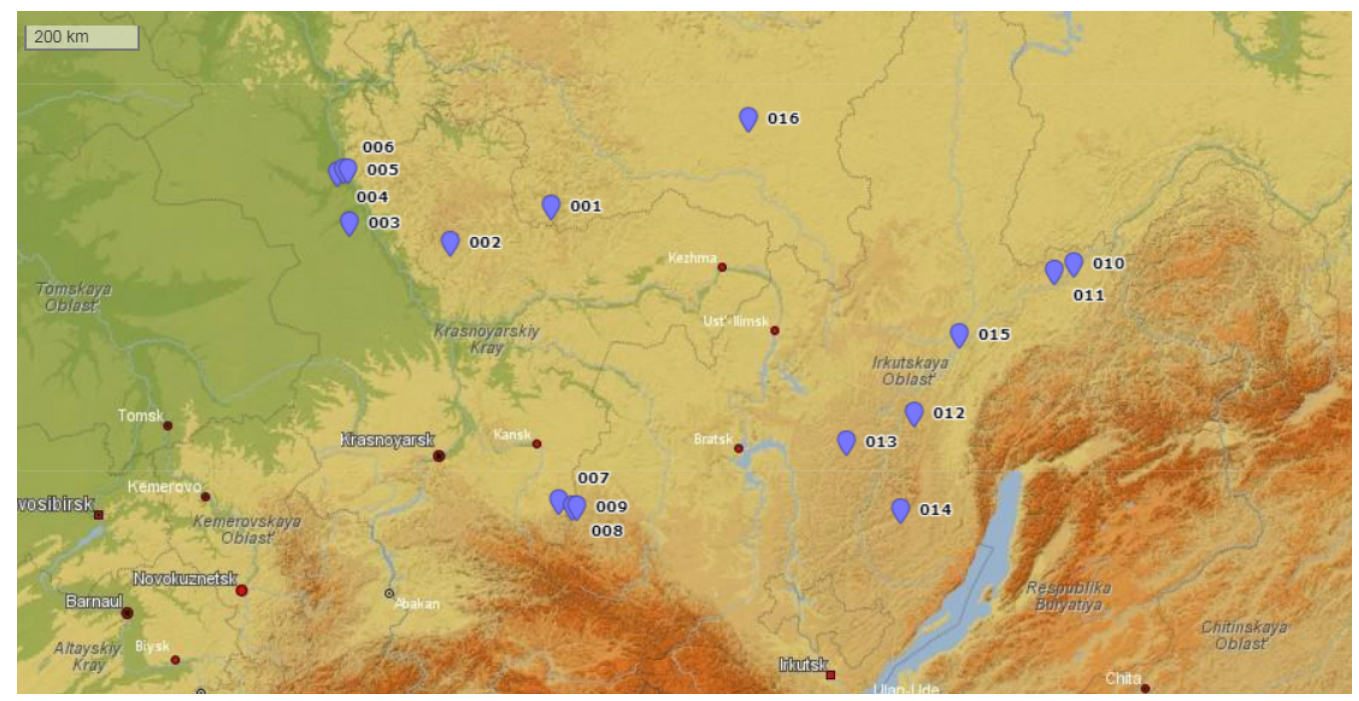

Figure 5. Location of Siberian fan reliefs from Table 1 on the map of Siberia. Point 016-the epicenter of the Tunguska catastrophe. To build the image, the Topomapper resource of the Nakarte.me application was used. 
The azimuth of the location of Siberian fan reliefs on the ground varies in the range from $4^{\circ}$ to $116^{\circ}$. If for the eastern points $(010,011,012$ and 013$)$ the direction of the central axis is close to the north direction, then the western structures of the stripes $(002,003,004$ and 005) are stretched to the east.

\section{RESULTS AND DISCUSSION}

Specific formations called Siberian fan reliefs were discovered in the airborne photographs in the 1970s-1990s. The images were taken from heights from $\sim 4 \mathrm{~km}$ to $\sim 30 \mathrm{~km}$. Siberian fan reliefs are structures elongated in one direction of stripes or scratches on the surface of the Earth. The size of such formations is from $6 \mathrm{~km}$ to $\geq 20 \mathrm{~km}$. Divergent stripes, as a rule, extended symmetrically, starting at one end of the structure, along the entire length of the object. The stripes are discontinuous; their width can reach 50 $\mathrm{m}$ with a length of more than $500 \mathrm{~m}$.

The sites on which the reliefs were found are located in a wide range of heights from an altitude of tens of meters above sea level to an altitude of over $900 \mathrm{~m}$. Geographically, all 15 structures considered in this work are in the range from $\sim 55^{\circ}$ to $\sim 60^{\circ}$ north latitude and between $\sim 90^{\circ}$ and $\sim 108^{\circ}$ east longitude. The direction of the central axis of the diverging bands varies from north to east-south-east.

What could be the reason for the formation of such structures of stripes? According to the height profiles in Figures 1-4, the relief of the terrain both decreases and increases with distance from the initial zone along the central axis. So, for example, the drawing of the Kazhma structure (Figure 2) demonstrates an ascent uphill. With a central axis length of $17 \mathrm{~km}$, the final point of the Kazhma formation is $\sim 250$ meters higher than the initial one. The presence of such formations makes it possible to exclude avalanches, landslides, mudflows, etc. from the list of phenomena leading to the emergence of Siberian fan reliefs.

Storms, hurricanes and other wind processes in these latitudes, as a rule, do not lead to stripe demolition of turf and woody vegetation. Moreover, in Figure 6 it can be seen that in the initial zone the scatter

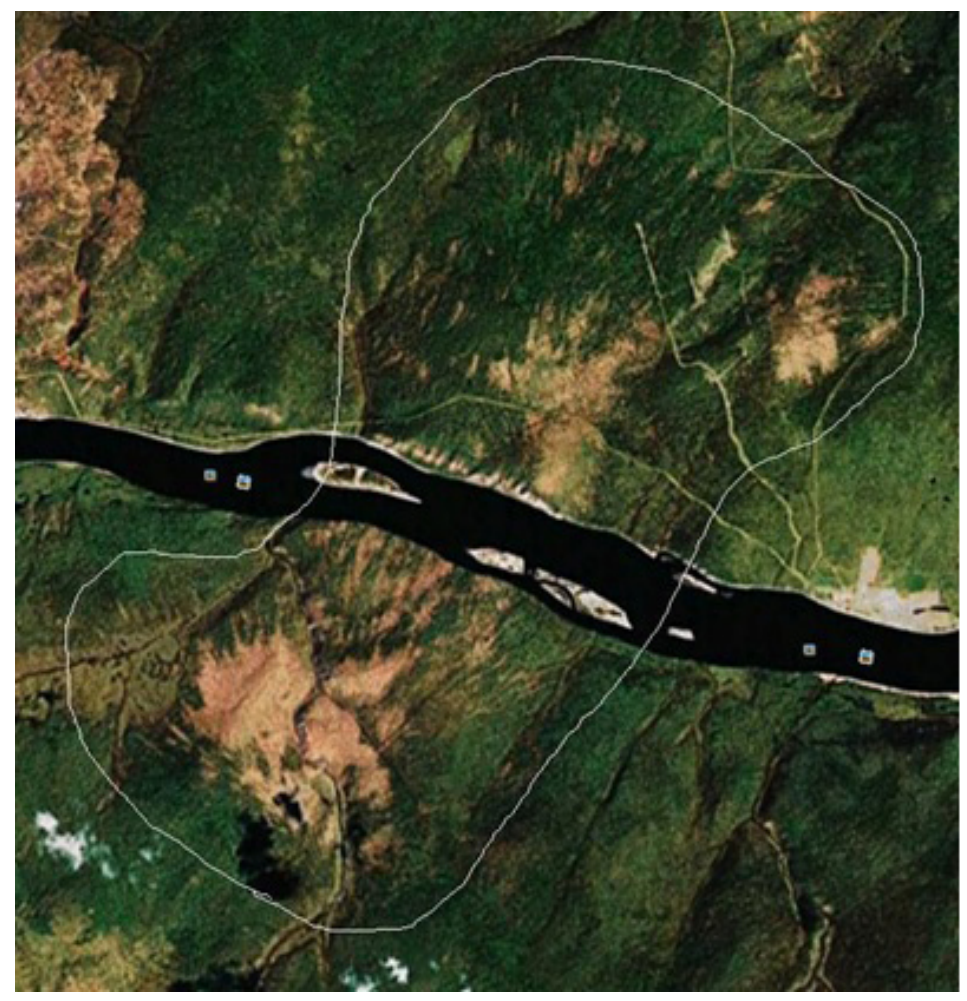

Figure 6. Fragment of an archive snapshot of Lenal formation courtesy of V. V. Burmakin. The photo was taken from a height of $20.84 \mathrm{~km}$. The coordinates of the image are $58^{\circ} 39^{\prime} 00.54 " \mathrm{~N}$; $110^{\circ} 47^{\prime} 45.66^{\prime \prime} \mathrm{E}$. 
angle of the directions of the stripes exceeds $100^{\circ}$. It is unlikely that the movement of air masses could be so multidirectional at the same time.

The sound and light effects of the Tunguska catastrophe were noted by local residents at distances of many hundreds of kilometers from the epicenter [2]. Considering the fact that the Tunguska cosmic body was a swarm of numerous fragments [3], it can be assumed that these Siberian fan reliefs are related to the Tunguska catastrophe.

Thus, at present, the reason for the formation of Siberian fan reliefs, as well as the time of their appearance on the Earth's surface, require further careful study.

\section{ACKNOWLEDGEMENTS}

The authors thank Valery Vitalievich Burmakin for the archival photographs he kindly provided.

\section{CONFLICTS OF INTEREST}

The authors declare no conflicts of interest regarding the publication of this paper.

\section{REFERENCES}

1. Lopatin, A.P. and Uskova, L.M. (2004) Traces of the Tunguska Meteorite Were Found on Space Images. Bulletin of Geodesy and Cartography, p. 6.

2. Gladysheva, O.G. (2014) The Tunguska Catastrophe: Pieces of a Puzzle. LAMBERT Academic Publishing.

3. Gladysheva, O.G. (2020) Swarm of Fragments from the Tunguska Event. Monthly Notices of the Royal Astronomical Society, 496, 1144-1148. https://doi.org/10.1093/mnras/staa1620 